\title{
Economic Diversification for Sustainable Development in Nigeria
}

\author{
Michael Chugozie Anyaehie, Anthony Chukwudi Areji \\ Department of Philosophy, University of Nigeria, Nsukka, Nigeria \\ Email: mikeanyaehie@gmail.com, tonyareji@yahoo.com
}

Received 15 February 2015; accepted 5 March 2015; published 6 March 2015

Copyright (C) 2015 by authors and Scientific Research Publishing Inc.

This work is licensed under the Creative Commons Attribution International License (CC BY). http://creativecommons.org/licenses/by/4.0/

c) (i) Open Access

\begin{abstract}
Nigeria operates mono commodity (petroleum) based economy. She just extracts the oil for export. The generated revenue is not effectively invested on diversification of the economy to develop a robust and stable economy. This is due to some socio-political challenges that border on individual interests and poor socioeconomic orientations that militate against industrialisation of the economy. The situation exposes the nation to both economic and socio-political instability as the economy fails to accommodate wide spectrum of people and sustain the basic needs of the populace. Nigeria should pragmatically address the challenges of poor industrialisation to diversify her economy.
\end{abstract}

\section{Keywords}

Economic Diversification, Stability, Sustainability, Development

\section{Introduction}

Nigeria is the most populated African nation with a population of about 160 million. The nation is made up of people of diverse cultures and religions. She is endowed with many natural resources scattered in different parts of the territory. At independence in 1960, the main source of the nation's revenue was agriculture and extraction of solid minerals. The discovery of petroleum in the country in the 1960s and the blooming of petroleum in the global market led to her over dependence on petroleum and a gradual but consistent neglect of agriculture and other sectors of the economy. Today petroleum accounts for over $90 \%$ of Nigeria's export revenue and over $80 \%$ of the government's budget (Jekwe, n.d.). Most of this petroleum revenue has been mismanaged through corruption, and disoriented, myopic and short term economic programmes. It is unfortunate that the different tiers of government in Nigeria cannot pay their workers talk less of embarking on any meaningful project without reliance on petroleum revenue. The situation has left the economy of the country at the mercy of the vagaries 
of petroleum market. Again, the neglect of other sectors of the economy has left majority of her work force unengaged or under-engaged, creating a large pool of unemployed that becomes easy tools for destabilisation of the country. The oil industry cannot engage significant number of the work force. There is an urgent need for Nigeria to diversify her economy to curb unemployment and stabilise her economy for sustainable national development.

\section{Sustainable Development}

The main goal of development is to satisfy human needs and aspirations. It involves the actualisation of human potentialities, and proper understanding and management of the environment and the resources therein for sustained human wellbeing. Sustainable Development is a continual enhancement of the quality of human life both for now and the future. The report of the World Commission on Environment and Development of the United Nations in 1983 popularly known as Brundtland Commission Report 1983 holds thus:

Sustainable development is development that meets the need of the present without compromising the ability of future generations to meet their own needs... In essence, sustainable development is a process of change in which the exploitation of resources, the direction of investments, the orientation of technological development; and institutional change are all in harmony and enhance both current and future potential to meet human needs and aspirations ("Towards Sustainable Development," Our Common Future, 1983).

The report identified two key concepts in the definition of sustainable development:

- the concept of "needs", in particular the essential needs of the world's poor, to which overriding priority should be given; and

- the idea of limitation by the state of technology and social organization on the environment's ability to meet present and future needs. (ibid)

The World Congress of Architects in June 1993 following Brundtland conception of sustainable development describes sustainability as "meeting our needs today without compromising the ability of future generations to meet their own needs" ("9 Sustainable Development Definition", An Architect’s Guide to Designing for Sustainability, 1993). Every nation should be sensitive to ensuring the sustained viability of its economy and development. Sustainable development involves consideration of three aspects of reality, namely: the physical environment, the socio-political and the economic. These three aspects of reality are very central in any bid to sustain any development. When any of these factors is lacking, such developmental policy is bound to fail. If any development emphasises one aspect, take for example, economic viability at the expense of environmental or socio-political sustainability that developmental programme cannot be sustained as the deterioration of the other sectors will stifle the economic interest. Hence, the UN 2005 World Summit on Sustainable Development Outcome Document sees environmental protection, social development and economic development as interdependent and mutually reinforcing pillars of sustainable development ("Sustainable Development." Wikipedia, The Free Encyclopedia).

Every development takes its toll on the environment. It provides the basic natural resources on which any development is built. The sustenance of physical environment entails that our environment, that is, vegetation and ecosystem, should be managed in such a way that its exploitation should not exceed its rate of renewal. Any sustainable development should, therefore, balance its deteriorating effect with the renewal ability of the environment. If the deteriorating effect of the development exceeds the rate of environmental renewal, with time the environment will no longer be capable to sustain the development. Technology helps the environment to cope with human needs. Technological development, therefore, should be sensitive to environmental sustainability. A non holistic consideration of impact of a direction of technology may solve some immediate challenges but creates greater one, like the use of nuclear reactors for electricity which portends great environmental disaster in the management of its bye product or in case of any mishap as manifested in the Fukushima Dsiichi nuclear reactor for electricity disaster in Japan.

The exploitation of non-renewable resources like fossil fuels and other minerals should be so managed that the rate of depletion and the economy of use should ensure that acceptable substitutes are provided. Natural resources are often undervalued as often times, their values are based on their cost of extraction and not on their renewability and the environmental impact, especially when their market is determined by external forces as is the case in Africa. The exploitation of the environment should not exceed its renewable capacity to maintain en- 
vironmental equilibrium for sustainability.

The socio-political dimension of development entails the sustenance of the society and its values. Socio-political sustainability involves maintenance of cohesion and stability of the society and its ability to work towards common goals which border on security, health, economic and social wellbeing, pursuit of aspirations and freedom of self expression. Viable development must ensure equity and socio-political stability both among the people of a generation and the future generation. Injustice breeds discontentment, strife and instability that frustrate any developmental programme. Sustainable development should respect cultural diversity and ensure individual and group uniqueness. There is always the danger of development over simplifying people's culture and creating one universal culture that often alienates people from their values, and dwarfs cultural creativity and enrichment of social interaction. UNESCO in 2001 made a Universal Declaration of Cultural Diversity and declares that cultural diversity is as necessary for humankind as biodiversity is for nature. Cultural diversity is one of the roots of development as it is a means to achieve a more satisfactory intellectual, emotional, moral and spiritual satisfaction (“Sustainable Development." Wikipedia, The Free Encyclopedia).

The central focus of development is the satisfaction of people's needs and aspirations. Any development programme must be economically viable for it to be sustained. Sustainable development requires meeting human economic needs both by increasing productive potential and ensuring equitable opportunity for all. Enhancing productive potential alone without due consideration of equity is not sustainable. To ensure socioeconomic sustainability, the basic needs of human survival should be of paramount priority. These needs border on job, food, health, clothing and shelter. In a situation where there are high productivity and riches, and these basic needs are not assured to the generality of people, there are bound to be general disenchantment, frustrations, antisocial activities and other crises that will cripple socioeconomic activities. Economic growth should involve participation of all, equity and non-exploitation of people to elicit dedication and harmony in the society. It should secure the needs and aspirations of both the present and future generations.

\section{Economic Diversity and Sustainable Development}

Economic diversification is a process of broadening the range of economic activities both in the production and distribution of goods and services. It does not necessarily entail increase in output but it enhances stabilisation of economies by diversifying their economic base. The issue of economic diversification should be viewed from the perspective of sustainable development to ensure long-term stability of the economy. Viewed from this angle, it has the capacity to fundamentally strengthen an economy's adaptive capacity and safeguards its long-term prospects in the face of depletion of the basic natural resources and the vagaries of economic fluctuations under the pressure of competition in globalisation.

Economic diversification has the propensity to meet the basic requirement for sustainable development like meeting the poor's basic needs which revolves around provision of job, food, health, clothing and shelter by opening diverse avenues of economic activity which accommodates broad spectrum of people. It also propels the expansion of environmental ability to meet people's needs by improving the technology, social organisation, diversity of areas of economic activity and not over exploiting one aspect of natural resources to the point of extinction and environmental degradation. Again, it creates a broad based economy that has the ability to secure equity both within and between generations (Zhang. n.d.).

\section{The Economic Situation of Nigeria}

Nigeria is a mono-economic nation with its economy heavily dependent on petroleum revenue which accounts for about $80 \%$ of government revenue and $90 \%$ of foreign exchange earnings. Before the prominence of petroleum industry, Nigerian economy was dependent on agriculture. The growth of petroleum industry in Nigeria brought about dramatic change in the nature of Nigerian economy. The high economic gains of the oil industry made the nation to abandon other sectors of the economy and depend solely on oil industry. The situation has led to non development of other sectors of the economy like exploitation of abundant solid minerals, agriculture, manufacturing industries and service industries. This has exposed the nation to economic instability occasioned by the vagaries of international oil markets, gross unemployment, poverty in the face of plenty, and a passive political leadership that is lukewarm in articulating and embarking on viable economic policies.

A critical look at the situation of Nigeria's economy and the different sectors (Table 1) shows that it is a mixed economy driven by both government and private enterprises. The government embarks on basic enter- 
prises that are hubs of socioeconomic activities like provision of electricity, transportation, portable water and primary industries. The private sector is a mixture of subsistent small, medium and large scale enterprises. Majority of the population engage on subsistent small enterprises with low capacity for improved productivity.

The economy can be structurally classified into three major sectors: primary sector-agriculture and natural resources extraction; secondary sector—processing and manufacturing; and tertiary sector-trade and services. Both the government and the private sectors operate on these major sectors of the economy. For sustainable development, these sectors are expected to grow and blend with each other. But this is not the case in Nigeria as there are poor infrastructures and human capacity to integrate them. The primary sector's produce gets to the tertiary sector or end user with little or no input from the secondary sector. The secondary sector which should consolidate and give enhanced value to primary sector's produce to boast the economy is poorly developed. Most of the primary sector's produce like agricultural and natural resources extractions do not go to the secondary sector (processing and manufacturing) which enhances their value, before getting to the market or the end users. Hence, primary goods get to their end user in the raw state attracting low economic value. This lack of effective participation of the secondary sector in the economic chain impoverishes the nation, exposes the nation to exploitation and slows down economic development and stability.

The primary sector dominates the nation's economy (Table 2). Between 1960 and 2009, it contributes 62.1 percent of her GDP. The secondary sector (manufacturing and building/construction) contributes average of 9.6 percent, and the tertiary sector (trade and services) contributes an average of 28.3 to the nation's GDP

Table 1. Economic sectors’ contribution to Nigerian GDP in percentage (Source: national bureau of statistics as contained in Sanusi, Lamido Sanusi, “Growth prospects for the Nigerian Economy”).

\begin{tabular}{ccccccc}
\hline Economic Sectors & Activity Sector & $1960-70$ & $1971-80$ & $1981-90$ & $1991-2000$ & $2001-09$ \\
\hline Primary Sector & Agriculture & 55.8 & 28.4 & 32.3 & 34.2 & 40.3 \\
& Extraction Industry & 4.7 & 21.8 & 34.9 & 33.7 & 24.5 \\
Secondary Sector & Manufacturing & 6.6 & 7.3 & 6.1 & 4.9 & 3.9 \\
& Building and Construction & 4.8 & 8.3 & 2.3 & 1.8 & 1.8 \\
Tertiary Sector & Trade & 12.8 & 17.6 & 14.5 & 13.8 & 14.0 \\
& Services & 15.3 & 16.5 & 9.8 & 11.5 & 15.5 \\
& Total Value & $\mathbf{1 0 0}$ & $\mathbf{1 0 0}$ & $\mathbf{1 0 0}$ & $\mathbf{1 0 0}$ & $\mathbf{1 0 0}$ \\
& Diversification Index & $\mathbf{0 . 2}$ & $\mathbf{0 . 4}$ & $\mathbf{0 . 4}$ & $\mathbf{0 . 4}$ & $\mathbf{0 . 3}$ \\
\hline
\end{tabular}

Table 2. Economic sectors’ contribution to Nigerian export in percentage (Source: CBN annual report and account statement on various issues in Sanusi, Lamido Sanusi, “Growth prospects for the Nigerian Economy”).

\begin{tabular}{|c|c|c|c|c|c|c|}
\hline Component & 2004 & 2005 & 2006 & 2007 & 2008 & 2009 \\
\hline Oil Export & 97.5 & 98.3 & 97.8 & 97.9 & 99.0 & 95.8 \\
\hline Total Non Oil Export & 2.5 & 1.7 & 2.2 & 2.1 & 1.0 & 4.2 \\
\hline Total & 100 & 100 & 100 & 100 & 100 & 100 \\
\hline \multicolumn{7}{|l|}{ Non Oil } \\
\hline Agriculture & 33.0 & 41.7 & 37.8 & 39.7 & 58.3 & 46.9 \\
\hline Minerals & 2.0 & 4.0 & 8.5 & 6.3 & 7.7 & 6.7 \\
\hline Semi Manufactured & 48.8 & 40.6 & 37.9 & 39.4 & 17.0 & 29.2 \\
\hline Manufactured & 5.0 & 9.8 & 11.1 & 10.3 & 8.7 & 9.1 \\
\hline Other Exports & 11.2 & 3.9 & 4.7 & 4.3 & 8.3 & 8.1 \\
\hline Total & 100 & 100 & 100 & 100 & 100 & 100 \\
\hline
\end{tabular}


(Sanusi, 2010). The secondary sector needs a boast for it to achieve its role for optimal utilisation of the nation's resources and integration of the economy.

The high hope of rapid development and industrialisation of the nation that accompanied her independence in 1960 has been crushed. The collapse of essential infrastructure for economic and industrial activity like electricity, transportation, portable water, investable fund; and inconsistent government policies on stimulation of industrial activities have discouraged the springing up of industries despite the fact that Nigeria with her large population and vast land is well suited to be the economic hub centre of Africa. Nigeria needs to utilise its large human and natural resources to develop the industrial sector for optimal utilisation of the resources and sustainable economic stability.

At the primary sector, Nigeria has drifted to a mono commodity economy based on petroleum. Agriculture was the main hub of Nigerian economy before the emergence of petroleum industry. It contributed about 55.8\% of the nations GDP in the 1960s and engaged over 70\% of Nigerian labour force. With heavy government support, it now contributes about $40 \%$ of the GDP after it had gone down to $28.4 \%$ in the 1970 s (Sanusi, 2010). It has not been able to fulfil its primary role of feeding the nation, providing raw materials for industries and profitably engaging the teaming unemployed. The sector has been neglected and its productivity is low. It still operates on peasant farming and relies on rudimentary farm implements and low technology which cannot effectively satisfy the needs of the operators and meet current agricultural needs of the nation, not to talk about actualising its potential of being a major foreign revenue earner of the nation.

Nigeria has large quantity of over 37 types of solid minerals spread across her vast land. Like agriculture, the exploitation of these minerals is neglected and left in the hands of local peasants who lack both the fund and expertise for their efficient and economic exploitation. The solid minerals can also contribute meaningfully to the nation's GDP and be a major foreign revenue earner if given the necessary attention.

Petroleum industry is the only sector that has been striving in Nigeria. It has "pushed Nigeria to the forefront of the global industry, making the country the sixth largest exporting and seventh largest producer of oil in the world” (Aigbedion and Iyayi, 2007). According to Sanusi (2010) of the Central Bank of Nigeria, Nigeria has the sixth largest gas reserves and the eighth largest crude oil reserves in the world. Despite Nigeria's high profile in the extraction and export of crude petroleum, the downstream sector of the industry is yet to develop. Nigeria still imports a substantial amount of refined oil for her domestic need. The other petrochemical industries that should accompany the oil industry are lacking. It is unfortunate that the huge oil extraction in the nation does not translate into development of petroleum allied industries and stimulation of diversity of the economy.

\section{The Impact of Petroleum Mono-Economy}

The neglect of other sectors of the economy has led to the non diversification and development of the economy to address the needs of the nation. The nation's fortune is tied to the dynamics of oil market. With the present aggressive measures being adopted by the international community to device alternative renewable source of energy, the fate of Nigeria as oil mono economy dependent nation is precarious.

Again the neglect of the development of other sectors of economy has created mass unemployment as only a marginal few can be absorbed by oil industry. It has limited opportunities for the rest of the population to participate in the national economy. Everyone including the government looks up to the oil in determining the standard of living, and since the other sectors of the economy are poorly developed, they cannot assure any standard. Hence, there are dissatisfaction and disgruntlement among the people. The situation creates a divide between the very rich, who operates on oil economy (government agencies and their cronies) and the very poor who operates on the mainstream of the economy (the workers, peasants and the small and medium scale entrepreneurs) with almost a complete vacuum in-between these two divides.

The over concentration on oil as the only major source of government revenue has adversely affected the socio-political stability of the nation. The quest for the control of oil revenue is what precipitates aggressive struggle to control the Federal Government by the different sections of the country. The federal nature of the nation has been truncated by the interest of any group that controls the Federal Government to control the oil revenue. All the tiers of the government have shown poor leadership and initiative to develop other sectors of the economy because of their overdependence on oil revenue. It is worrisome for governments to solely depend on oil revenue for them to pay their workers talk less of providing any infrastructure. The politics of control of oil revenue has over heated the polity that discussions on national economy revolve around the sharing of oil 
revenue and not on the development and sustainability of the economy through diversification and engagement of the teaming work force in productive ventures for wealth creation. The concept of job creation revolves around government expanding its bureaucratic structures and sustaining them with oil revenue and not creating structures for the gainful engagement of the people in productive ventures.

It is pertinent to call to mind here that petroleum is a non renewable resource. It will one day be exhausted or looking at the global quest for renewable and alternative source of energy, the oil market will slump any time. The future of the nation depends on how effectively the oil revenue is utilised in establishing basic sustainable economic structures that will continue to boast her economy. The nation should use the accruing oil revenue to embark on aggressive industrialisation and diversification of the economy.

\section{Challenges of Economic Diversification in Nigeria}

Nigerian government has made some efforts in the diversification of the economy. But government policies in this area have not been effective due to a number of challenges which include: macroeconomic orientation, poor infrastructure, weak economic institutions, poor corporate governance, poor educational orientation, endemic corruption and insecurity.

\subsection{Macroeconomic Orientation}

The nation's economy does not emphasis productivity. It emphasises sharing of wealth and who gets what. This orientation is deepened in the nation's psyche by the easy revenues gotten from extraction of natural resources, especially petroleum. There is a dearth in investment of resources on long term productive ventures. Loans from both government and private sectors operate on high interest rate and can only be economically used for only short term projects. Hence, most of the loaned funds are used for trading (especially importation) which involves high turnover. This affects investing on the industrialisation of the economy. Again, most of the nation's revenue revolves around the political class who wastes it on luxurious life style and patronage of foreign goods. This accounts for the government's waste of resources on bogus white elephant projects that are never finished and when finished cannot be maintained. The main stream of the economy, the business and working class, is deprived of the necessary resources to encourage skill acquisition, industrialisation and productivity. Nigerian political office holders are among the highest paid while her workers are among the list paid in the world. Hence, her professionals and other elites abandon their areas of specialisation and either juggle for political positions or leave the country for a better condition of service. There is urgent need for the nation to re-channel her resources towards productivity and not bureaucracy. The national resources should be channelled towards creating productive jobs and industrialisation. The importation of foreign goods should be restricted to what is necessary to give indigenous industries the opportunity to strive.

\subsection{Poor Infrastructure}

Development and diversification of Nigerian economy face the challenge of poor economic and social infrastructure. Bad road network, erratic power supply, scarce potable water, poor healthcare facilities, poor transportation and communication network, scarcity of investible fund, and poor and unstable educational system are among the main constraints to economic development and diversification of the economy. The nation needs to invest its resources wisely on technological development, skill acquisition and human development, and provision of economic and social infrastructure for her to be on the path of sustainable development. Improved infrastructure will create ample opportunity for her population to be innovative and productive which will boast production of goods and service for both local consumption and export.

\subsection{Poor Corporate Governance and Institutions}

To kick-start the economy, the government needs to be seriously committed to the course. There is poor state of corporate governance and institutions in the country due to poor ethical standards in both public and private organisations which frustrate the achievement of the goals of different economic and social policies. Nigerian government has over and over resolved to embark on economic development and diversification but most of the policies yielded marginal effect as they were truncated along the course due to weak institutions and political instability occasioned by personal and sectional interests. 


\subsection{Endemic Corruption and Mismanagement of Resources}

The endemic nature of corruption in Nigeria makes it very difficult to effectively manage the nation's economy and sustain any policy that will transform the economy. The economy and its policies are corruptibly sabotaged to satisfy individual or sectional interests. The huge earnings of the nation end in private hands. They do not make significant impact on the living standard of the people or on the economic fortune of the nation. Nigeria is a place where there are millionaires and billionaires who have no line of business but are only friends to the government. They employ no body and produce nothing to justify their wealth. It is the endemic corruption that denies the nation the most needed revenue for infrastructural and economic development.

\subsection{Poor and Unstable Educational System}

The Nigerian educational system is tailored to bureaucracy and not to productivity. Nigerian educational system produces educated graduates without skills. Certificate acquisition is treasured above skill and productivity. It is unfortunate that the nation is playing down skill acquisition and technological institutions for universities. This has led to massive pool of unemployed graduates which continue to strain the economy. The educational system needs to be restructured to produce the right graduates with requisite skills for the economy. Again, the educational system has to be well funded to create the enabling environment for academic exercise and put an end to incessant disruptions of academic activities.

\section{Conclusion}

Economic diversification is the process of expanding the range of economic activities both in the production and distribution of goods and services. It is the widening of the economy to create opportunities for diverse economic activities to create a broad based economy. It provides job for wide spectrum of people and stabilises the economy against economic fluctuations of commodities, and sustains the developmental prospects of nations. Nigeria needs to use her huge oil revenue to diversify her economy to create job opportunities and satisfy the basic needs of her large population and sustain her quest for development. To achieve this, she has to conscientiously confront the challenges that hinder her economic diversification to reposition herself on the path of productivity. These challenges make industrial investment in the country very expensive and unattractive.

Diversified economy will stabilise Nigeria's economy against the vagaries of oil market, and provide opportunities for the satisfaction of needs and aspirations of her population. Different sections of the nation and tiers of government should develop other aspects of economy where they have comparative advantage. The efforts should accommodate the key requirements of sustainable development which include meeting the basic needs of man (job, food, health, clothing and shelter), maintaining equity both within and between generations, improving on technology and social organisation to expand the environmental ability to sustain human needs.

\section{References}

(1983). Towards Sustainable Development. Our Common Future. Report of the World Commission on Environment and Development, UN Documents: Gathering a Body of Global Agreements, The NGO Committee on Education of the Conference of NGOs. http://www.un-documents.net/ocf-02.htm

9 Sustainable Development Definition (1993). An Architect's Guide to Designing for Sustainability. http://www.comarchitect.org/WebHelp/9_sustainable_development_definition.htm

Aigbedion, I., \& Iyayi, S. E. (2007). Diversifying Nigeria’s Petroleum Industry. International Journal of Physical Sciences, 2, 263-270.

http://www.academicjournals.org/IJPS

http://www.academicjournals.org/ijps/pdf/pdf2007/oct/aigbedion\%20and\%20iyayi.pdf

Jekwe, I. Assessing the Future of Nigeria’s Economy: Ignored Threats from the Global Climate Change Debacle. Africa Economic Analysis. http://www.afbis.com/analysis/climate_change.htm

Sanusi, L. S. (2010). Growth Prospects for the Nigerian Economy. Convocation Lecture Delivered at the Igbinedion University Eighth Convocation Ceremony, Okada.

http://www.cenbank.org/out/speeches/2010/gov_convocation_lecture-igbinedion-university-okada_2010.pdf 
Sustainable Development. Wikipedia, The Free Encyclopedia. http://en.wikipedia.org/wiki/Sustainable_development Zhang, L.-Y. Economic Diversification and Sustainable Development: Linkages and Barriers.

http://unfccc.int/files/adaptation/adverse_effects_and_response_measures_art_48/application/pdf/zhang_-_economic_dive rsification and sd - linkages and barriers.pdf 